\title{
Malignant meningioma of the lateral ventricle
}

\author{
Case report
}

\author{
Tahsin Erman, M.D., A. ÍSKender GöÇER, M.D., Metin Tuna, M.D., \\ ŞEYDA ERdoĞan, M.D., AND SUZAN ZoRLUdEMIR, M.D.
}

Departments of Neurosurgery and Pathology, Çukurova University School of Medicine, Adana, Turkey

\begin{abstract}
This 65-year-old man presented with a very rare malignant meningioma in the trigonum of the right lateral ventricle. Neurological examination showed bilateral papilledema. Magnetic resonance imaging revealed a solid, enhancing tumor in the right trigonum with a hypointense cystic component located in the center of the tumor. The lesion was totally resected via a superior parietooccipital transcortical approach. Histological examination showed an anaplastic (malignant) meningioma with architectural disarray, high mitotic activity (20/10 hpf), necrosis, and cytological atypism. As in our case, heterogeneous signal, due to necrotic tissue and frequently demonstrated on both $\mathrm{T}_{1}-$ and $\mathrm{T}_{2}-$ weighted sequences, is suggestive of an aggressive type of meningioma.
\end{abstract}

\section{KEY WORDS • intraventricular lesion • malignant meningioma • tumor resection}

Meningiomas are common intracranial tumors comprising 10 to $15 \%$ of the all brain neoplasms, the vast majority of which are benign. ${ }^{3,5,10,12}$ Intraventricular meningiomas are rare tumors, comprising only 0.5 to $5 \%$ of all intracranial meningiomas. To our knowledge, only a few cases of malignant anaplastic meningioma of the lateral ventricle have been reported. ${ }^{4}$ In this report, we describe a patient with an anaplastic (malignant) meningioma of the lateral ventricle and summarize the radiological and histological features of this case.

\section{CASE REPORT}

This 65-year-old man was admitted to our hospital with a history of seizure and headache. On neurological examination we found bilateral papilledema. Magnetic resonance imaging revealed a lesion that was isointense and slightly hypointense to gray matter on $\mathrm{T}_{1}$-weighted images and hyperintense to gray matter on $\mathrm{T}_{2}$-weighted images; we observed an intense and heterogeneous contrast-enhancing solid lesion located within the trigonum of lateral ventricle. A hypointense signal was demonstrated on $\mathrm{T}_{1}$ weighted MR images after Gd injection (Fig. 1). Digital

Abbreviation used in this paper: $\mathrm{MR}=$ magnetic resonance. subtraction angiography revealed an enlargement of the anterior choroid artery and vascular blushing in the region of the tumor. A right-sided parietooccipital craniotomy was performed, and total resection of the neoplasm was achieved via a superior parietooccipital transcortical approach; however, the patient died postoperatively of complications related to an intracerebral hemorrhage.

Multiple blocks from the resection specimens were fixed in formalin, embedded in paraffin, sectioned, and stained with $\mathrm{H} \& \mathrm{E}$. Microscopic examination showed an anaplastic (malignant) meningioma with architectural disarray, high mitotic activity (20/10 hpf), necrosis, and cytological atypism (Fig. 2).

\section{DISCUSSION}

Intraventricular meningiomas arise generally within the lateral ventricles and more rarely in the third and fourth ventricles. ${ }^{3,5,10,12}$ The incidence of meningiomas within the lateral ventricle varies from $0.5^{13}$ to $4.5 \%$ (Scheithauer BW, 2002, unpublished data) of all meningiomas. Ten to $15 \%$ of all meningiomas are considered malignant. ${ }^{2,9}$

Two histopathological types of intraventricular meningiomas exist: one that arises from the choroid plexus and grows within the ventricle and another that arises from the 


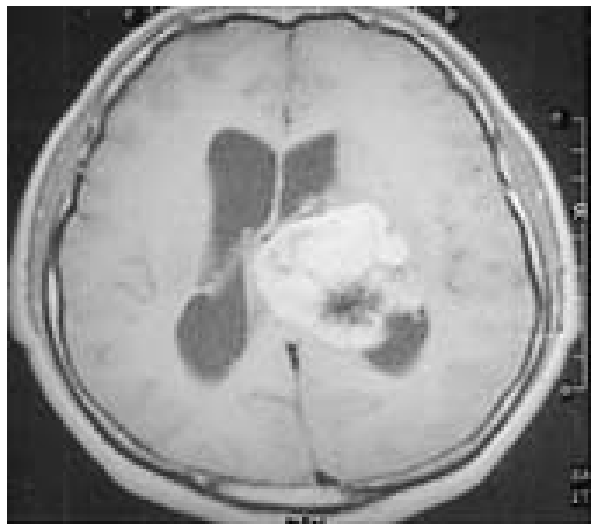

Fig. 1. Postcontrast $\mathrm{T}_{1}$-weighted axial MR image revealing a solid enhancing tumor within the right trigonum of lateral ventricle with a hypointense cystic component located in the center of the tumor.

tela choroidea and grows partly within the ventricle and partly into the surrounding brain (Scheithauer BW, 2002, unpublished data). Intraventricular meningiomas arise from the connective tissue of the villi or from the stroma or the arachnoid of the choroid plexus itself, which is abundant in arachnoidea. ${ }^{5,8}$ Their occurrence depends on the presence of this structure.

A review of the histological descriptions of 50 intraventricular meningiomas showed that these tumors are predominantly fibrous, fibroblastic, or psammomatous, with the exception of one angioblastic meningioma. ${ }^{10,12}$ In a smaller series of 10 intraventricular meningiomas reported by Criscuolo and Symon, ${ }^{1}$ the authors detailed a somewhat different distribution of histological types; there were five meningotheliomatous, three angiomatous, one fibroblastic, and one malignant lesion. A few cases of an anaplastic (malignant) meningioma in this location and age group have been reported. Malignant anaplastic meningiomas are an uncommon subtype that contain the following histological features: increased cellularity, prominent nucleoli, patternless or sheetlike growth, a high mitotic index ( $\geq 20 / 10 \mathrm{hpf}$ ), and conspicuous often palisading necrosis ${ }^{6}$ (Scheithauer BW, 2002, unpublished data).

Magnetic resonance imaging is most useful in detecting these masses. It can be performed to evaluate tumor location, size, and extent and although it aids in differentiating paratrigonal tumors from intraventricular neoplasms, it does not always help in eliminating alternative diagnoses. ${ }^{3,5,13}$ Meningiomas are characteristically hypointense to isointense on $\mathrm{T}_{1}$-weighted and isointense to hyperintense on $\mathrm{T}_{2}$-weighted MR images, and the tumor uniformly enhances after contrast administration on MR imaging. Trigonal tumors are homogeneous and associated with localized dilation of the lateral ventricle, enlargement of the choroidal arteries and engulfment of the choroid plexus. ${ }^{3,13}$ Paratrigonal tumors displace the choroid plexus and compress the lateral ventricles, shifting the midline to the contralateral side. A heterogeneous signal due to necrotic tissue and frequently demonstrated on both $\mathrm{T}_{1}$ - and $\mathrm{T}_{2}$-weighted MR imaging sequences is suggestive of an aggressive type of meningioma, as in our case.

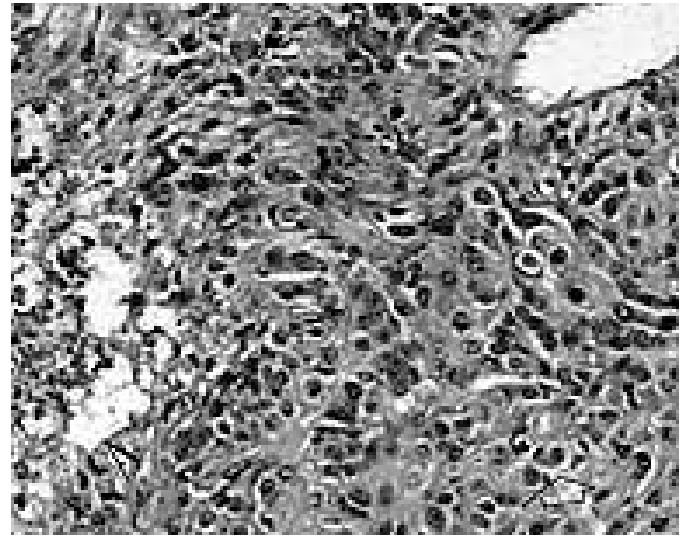

Fig. 2. Photomicrograph showing high mitotic activity (arrow), cytological atypism, and necrosis (arrowhead) in anaplastic (malignant) meningioma. H \& E, original magnifcation $\times 200$.

Intraventricular meningiomas are relatively resistant to most forms of therapy other than excision, and their total removal often results in cure or provides a long period of palliation. Radiotherapy is effective for preventing recurrence in cases of partially resected meningiomas and malignant anaplastic meningiomas. ${ }^{1,7,12}$ Embolization and gamma knife surgery may be an alternative treatment for intraventricular malignant meningiomas in which resection appears difficult. ${ }^{10-12}$ Malignant anaplastic meningiomas have higher local recurrence and lower survival rates than their benign counterparts. ${ }^{2}$

\section{CONCLUSIONS}

Anaplastic malignant meningiomas constitute a rare subset of meningiomas and exhibit a marked propensity for postsurgical recurrence. To our knowledge, malignant anaplastic meningioma of the lateral ventricle is a rare entity, of which only a few cases have been reported. A heterogeneous signal due to necrotic tissue and frequently demonstrated on both $\mathrm{T}_{1}$ - and $\mathrm{T}_{2}$-weighted MR images is suggestive of an aggressive type of meningioma as in our case.

\section{References}

1. Criscuolo GR, Symon L: Intraventricular meningioma. A review of 10 cases of the National Hospital, Queen Square (1974-1985) with reference to the literature. Acta Neurochir 83:83-91, 1986

2. Goyal LK, Suh JH, Mohan DS, et al: Local control and overall survival in atypical meningioma: a retrospective study. Int J Radiat Oncol Biol Phys 46:57-61, 2000

3. Jelinek J, Smirniotopoulos JG, Parisi JE, et al: Lateral ventricular neoplasms of the brain: differential diagnosis based on clinical, CT, and MR findings. AJR 155:365-372, 1990

4. Kamiya K, Inagawa T, Nagasako R: Malignant intraventricular meningioma with spinal metastasis through the cerebrospinal fluid. Surg Neurol 32:213-218, 1989

5. Kloc W, Imielinski BL, Wasilewski W, et al: Meningiomas of the lateral ventricles of the brain in children. Childs Nerv Syst 14:350-353, 1998

6. Louis DN, Scheithauer BW, Budka H, et al: Meningiomas, in Kleihues P, Cavenee WK (eds): World Health Organization 


\section{Malignant lateral ventricle meningioma}

Classification of Tumours. Pathology and Genetics of Tumours of the Nervous System. Lyon: IARC Press, 2000, pp 176-184

7. Lunsford LD: Contemporary management of meningiomas: radiation therapy as an adjuvant and radiosurgery as an alternative to surgical removal? J Neurosurg 80:187-190, 1994

8. Mani RL, Hedgcock MW, Mass SI, et al: Radiographic diagnosis of meningioma of the lateral ventricle: Review of 22 cases. J Neurosurg 49:249-255, 1978

9. Ojemann SG, Sneed PK, Larson DA, et al: Radiosurgery for malignant meningioma: results in 22 patients. J Neurosurg (Suppl 3) 93:62-67, 2000

10. Piepmeier JM, Westerveld M, Spencer DD, et al: Surgical management of intraventricular tumors of the lateral ventricles, in Schmidek HH, Sweet WH (eds): Operative Neurosurgical Techniques: Indications, Methods, and Results. Philadelphia: WB Saunders, 1995, pp 725-738
11. Terada T, Yokote H, Tsuura M, et al: Presumed intraventricular meningioma treated by embolization and the gamma knife. Neuroradiology 41:334-337, 1999

12. Tew JM Jr, Larson JJ: Intraventricular meningioma, in Kaye AH, Black PM (eds): Operative Neurosurgery. London: Harcourt Publishers, 2000, pp 575-585

13. Yoon HK, Kim SS, Kim IO, et al: MRI of primary meningeal tumours in children. Neuroradiology 41:512 516, 1999

Manuscript received April 16, 2003.

Accepted in final form July 15, 2003.

Address reprint requests to: Tahsin Erman, M.D., Department of Neurosurgery, Çukurova University School of Medicine, Balcalı, Adana 01330, Turkey. email: ermant@cu.edu.tr. 